\title{
BLOQUEO RETROCLAVICULAR CONTINUO DEL PLEXO BRAQUIAL, EXPERIENCIA ACUMULADA EN CLÍNICA SANTA MARÍA
}

Yarur Spencer Carlos ${ }^{1}$, Troncoso Hugot María Ignacia ${ }^{1}$, Pinto Ramírez Lorena ${ }^{1}$, Manzano Pérez Constanza ${ }^{1}$, Bastías Moraga Fernanda ${ }^{1}$, Fariña Roggendorf Gabriela ${ }^{1}$

1 Clínica Santa María.

Introducción: El abordaje retroclavicular del plexo braquial es una técnica regional novedosa, que ofrece múltiples ventajas frente a al resto de abordajes descritos. Destaca especialmente una muy buena visualización ecográfica, tanto de elementos anatómicos como de la aguja en plano, y un posicionamiento visible y estable en la instalación del catéter.

Objetivo General: Describir serie de casos de bloqueos retroclaviculares continuo con catéter, según variables demográficas, diagnóstico asociado, evaluación del dolor postoperatorio según Escala Visual Análoga (EVA), y complicaciones asociadas al catéter retroclavicular.

Material y Métodos: Estudio descriptivo, retrospectivo, se realizó una revisión de fichas clínicas de todos los pacientes sometidos a procedimientos quirúrgicos en los cuales se les realizó un bloqueo de plexo braquial por vía retroclavicular ecoguiado con instalación catéter en Clínica Santa María, en un periodo de 18 meses (enero de 2015 a julio de 2016). Se contó con la autorización del Comité de ética institucional. Se recopilaron datos de edad, sexo, intervención quirúrgica, evaluación del dolor (EVA) al primer y segundo día postoperatorio, estadía hospitalaria post operatoria y complicaciones asociadas al catéter reportadas por la unidad de manejo del dolor. Resultados se reportan como mediana (Rango).

Resultados: Se recolectaron un total de 53 pacientes, edad promedio de 41,3 años (ds 17,3), siendo en su mayoría varones $54 \%$ (n: 28 ), las intervenciones fueron en su principalmente de origen traumatológicas, mayormente fracturas antebrazo (n: 23), seguidas por fracturas de mano y muñeca (n: 8). En cuanto a la evaluación del dolor, la mediana de este el primer día con EVA estático y dinámico de $0(0-6)$ y $0(0-10)$, y el segundo día de $0(0-3)$ y $0(0-6)$. Un $69 \%$ (n: 36 ) de los pacientes fueron dados de alta el primer día postoperatorio, en su mayoría ( $86 \%$, n: 28$)$ con el catéter retroclavicular y bomba elastomérica instalada, en los restantes fue retirada previa al alta por indicación del médico tratante. La media de estadía fue de 1 días (0-18). La tasa de falla de catéter fue de $1,9 \%$ (n: 1$)$, secundaria a desplazamiento.

Conclusiones: En esta serie, el abordaje retroclavicular del plexo braquial ecoguiado, con instalación de catéter y administración continua de anestésico local mediante bomba elastomérica mostró ser una alternativa altamente efectiva en el manejo del dolor postoperatorio con una muy baja tasa de falla.

\section{Referencias}

1. Charbonneau j. The Ultrasound-Guided Retroclavicular Block A Prospective Feasibility Study. Regional Anesthesia and Pain Medicine, 09-2015. 40, 605-609.

2. Zhi Yuen Beh. Posterior parasagittal in-plane Ultrasoundguided infraclavicular brachial plexus block-a case series Beh et al. BMC Anesthesiology (2015) 15:105 Palabras claves: retroclavicular ultrasound block, peripheral nerve block, brachial plexus block.

Tabla 1. Se muestra el valor de mediana para cada evaluacion de EVA post operatorio

\begin{tabular}{|ccc|}
\hline & EVA Post Operatorio \\
\hline EVA E día 1 & Mediana & Rango \\
EVA D día 1 & 0 & $0-6$ \\
EVA E día 2 & 0 & $0-10$ \\
EVA D día 2 & 0 & $0-3$ \\
\hline
\end{tabular}

E (estático); D (dinámico). 